\title{
Variations in gene organization and DNA uptake signal sequence in the folP region between commensal and pathogenic Neisseria species
}

\author{
Yvonne Qvarnstrom*1,2 and Gote Swedberg ${ }^{1}$
}

\author{
Address: ${ }^{1}$ Department of Medical Biochemistry and Microbiology, Uppsala University, PO Box 582, SE-751 23 Uppsala, Sweden and ${ }^{2}$ Division of \\ Parasitic Diseases, National Center for Infectious Diseases, Centers for Disease Control and Prevention, mail stop F36, 4770 Buford Highway, \\ Atlanta, GA 30341, USA \\ Email: Yvonne Qvarnstrom* - bvp2@cdc.gov; Gote Swedberg - Gote.Swedberg@imbim.uu.se \\ * Corresponding author
}

Published: 17 February 2006

BMC Microbiology2006, 6:II doi:10.1I86/I47|-2/80-6-II
Received: 19 July 2005

Accepted: 17 February 2006

This article is available from: http://www.biomedcentral.com/I47I-2/80/6/II

(c) 2006Qvarnstrom and Swedberg; licensee BioMed Central Ltd.

This is an Open Access article distributed under the terms of the Creative Commons Attribution License (http://creativecommons.org/licenses/by/2.0), which permits unrestricted use, distribution, and reproduction in any medium, provided the original work is properly cited.

\begin{abstract}
Background: Horizontal gene transfer is an important source of genetic variation among Neisseria species and has contributed to the spread of resistance to penicillin and sulfonamide drugs in the pathogen Neisseria meningitidis. Sulfonamide resistance in Neisseria meningitidis is mediated by altered chromosomal folP genes. At least some folP alleles conferring resistance have been horizontally acquired from other species, presumably from commensal Neisseriae. In this work, the DNA sequence surrounding folP in commensal Neisseria species was determined and compared to corresponding regions in pathogenic Neisseriae, in order to elucidate the potential for inter-species DNA transfer within this region.

Results: The upstream region of folP displayed differences in gene order between species, including an insertion of a complete Correia element in Neisseria lactamica and an inversion of a larger genomic segment in Neisseria sicca, Neisseria subflava and Neisseria mucosa. The latter species also had DNA uptake signal sequences (DUS) in this region that were one base different from the DUS in pathogenic Neisseriae. Another interesting finding was evidence of a horizontal transfer event from Neisseria lactamica or Neisseria cinerea that introduced a novel folP allele to the meningococcal population.

Conclusion: Genetic recombination events immediately upstream of folP and horizontal transfer have resulted in sequence differences in the folP region between the Neisseria species. This variability could be a consequence of the selective pressure on this region exerted by the use of sulfonamide drugs.
\end{abstract}

\section{Background}

Horizontal gene transfer via natural transformation is believed to be the main mechanism to generate genetic diversity among Neisseriae [1-3]. Horizontal transfer has for example contributed to the spread of resistance to pen- icillin in pathogenic Neisseriae, where the origin of the transforming DNA was traced to commensal Neisseria species [4]. Sulfonamide resistance in some strains of Neisseria meningitidis (the meningococcus) has also been acquired by horizontal transfer [5]. As evidence, a mosaic 


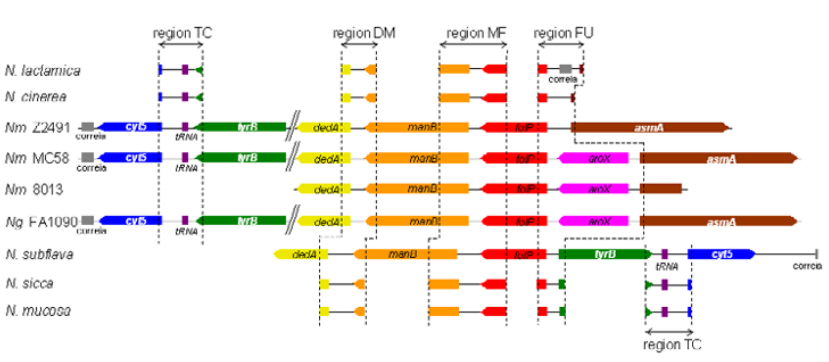

Figure I

Comparison of gene arrangements in human Neisseriae. The $N$. subflava sequence (accession number AJ58I792 in the EMBL database) is displayed in alignment with corresponding parts from other Neisseria species. Open reading frames are visualized as colored block arrows (the tip of each arrow symbolizing the stop codon) and labeled with their designations according to the text. Non-coding regions are visualized as solid lines. The $\operatorname{ded} A$ gene and the Correia element in $N$. subflava were only partially sequenced. The symbol // means that I $3 \mathrm{~kb}$ sequence separating tyr $B$ from dedA has been omitted in the figure. The intergenic regions are defined by dotted vertical lines and designated TC (tyrB-cyt5), DM (dedA-manB), MF (manB-folP) and FU (folP-upstream), respectively.

pattern of fragments with high sequence divergence was detected in the chromosomal folp gene, the sulfonamide resistance determinant. The origin of the transforming DNA is still unknown, but presumable donors are commensal Neisseria species.

We have previously demonstrated that commensal Neisseria isolates from healthy carriers exhibit high level sulfonamide resistance, most likely due to sulfonamide-resistant variants of folP [6]. These commensal folP genes differ substantially from previously described folP genes, but the findings suggest that sulfonamide resistance is a property carried among species of the commensal flora. Thus, the commensal flora can be a reservoir of sulfonamide resistance genes that might be transferred to pathogenic species.

Efficient transformation is dependent upon a reasonable sequence similarity between donor and recipient to facilitate homologous recombination. In addition, DNA uptake in pathogenic Neisseriae is markedly enhanced by the presence of a DNA uptake signal sequence (DUS) in the donor DNA [7,8]. Thus, the sequence within and immediately surrounding folP, especially the presence of DUS in that region, should influence how efficient commensal Neisseria species may transfer sulfonamide resistance to Neisseria meningitidis. This work presents the gene organization and the distribution of DUS in the folP region in some commensal Neisseria species and compares these to the corresponding parts of the genomes

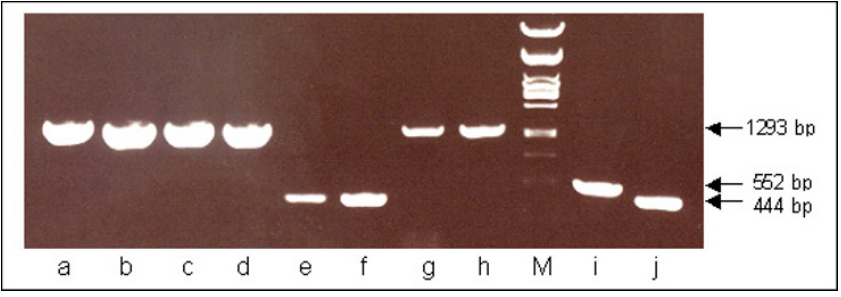

Figure 2

PCR amplification of the region between folP and asmA in Neisseriae. A 1293 base pair product denotes the presence of aroX between folP and asmA. M: molecular marker; a: Neisseria meningitidis $(\mathrm{Nm})$ strain $952\left(\mathrm{Su}^{\mathrm{S}}\right)$; b: $\mathrm{Nm}$ I0I4 (Su $\left.{ }^{S}\right)$; c: Nm BT054 (Sus); d: Nm 4 I 8 (SuR); e: Nm 3976

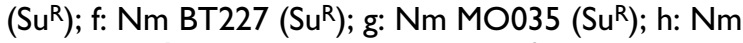
MOI $24\left(\mathrm{Su}^{\mathrm{R}}\right)$; i: Neisseria lactamica $\left(\mathrm{Su}^{\mathrm{S}}\right)$; j: Neisseria cinerea $\left(\mathrm{Su}^{\mathrm{S}}\right) . \mathrm{Su}^{\mathrm{S}}=$ sulfonamide-susceptible, $\mathrm{Su} \mathrm{R}^{\mathrm{R}}=$ sulfonamideresistant.

from three Neisseria meningitidis strains and Neisseria gonorrhoeae FA1090.

\section{Results}

\section{Gene organization in commensal Neisseriae}

The sequence surrounding folP was determined for Neisseria subflava by sequencing $6.8 \mathrm{~kb}$ of the genome. (N. subflava was chosen because sulfonamide-resistant commensal Neisseriae found in healthy carriers were phenotypically characterized as being most related to this species [6]). The corresponding sequences from $N$. meningitidis strains MC58 [9] and Z2491 [10], as well as N. gonorrhoeae FA1090 [11] were aligned with the $N$. subflava sequence. Included in this comparison was also a sequence from the on-going genome sequencing project of $N$. meningitidis strain 8013 (The Pasteur Institute, France). PCR primers designed from this alignment were then used to determine the gene order surrounding folP in one strain each of $N$. sicca, N. cinerea, N. lactamica and N. mucosa. The results are outlined in Figure 1 (see Additional file for sequence data). N. subflava, N. sicca and N. mucosa had identical gene order: directly downstream of folP was a putative phosphomanno-/phosphoglucomutase family gene (designated $\operatorname{man} B$ ), followed by a putative membrane-associated gene belonging to the dedA family ( $\operatorname{ded} A)$. Upstream of folP was an aromatic amino-acid amino-transferase gene ( $t y r B)$, followed by a $t R N A$-Arg gene, an open reading frame similar to a cytochrome 5 gene $(c y t 5)$ and a copy of the Correia repeat unit [12].

$N$. gonorrhoeae, N. lactamica, N. cinerea and the N. meningitidis strains had the same gene succession as N. mucosa/ $N$. sicca/N. subflava downstream of folP, but the genes found upstream of folP were completely different. Instead of being located upstream folP, the gene sequence tyrB$t R N A$-cyt5-Correia was in these species located $14 \mathrm{~kb}$ 
I.

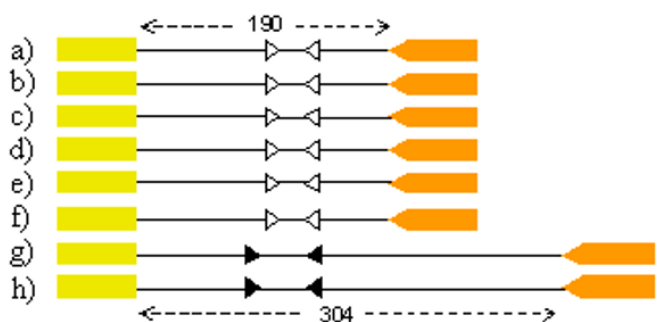

II.

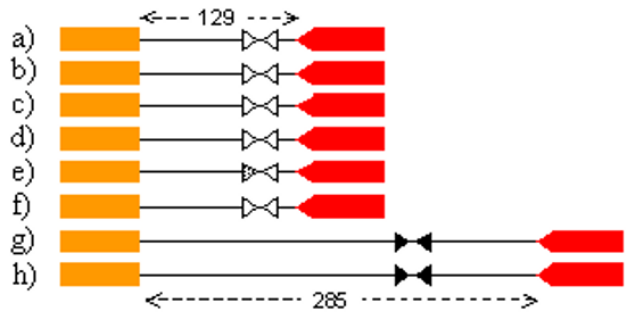

III.

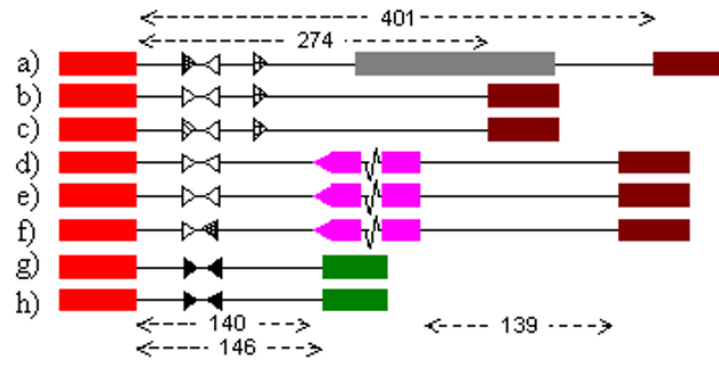

IV.

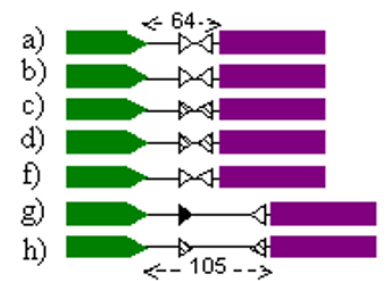

Figure 3

Enlargement of the intergenic regions from Figure $I$. I: region DM. II: region MF. III: region FU. IV: part of region TC. The order of the strains is as in Figure I: a) Neisseria lactamica; b) Neisseria cinerea; c) N. meningitidis Z249I; d) N. meningitidis MC58; e) N. meningitidis 80 I3; f) N. gonorrhoeae; g) Neisseria subflava; h) Neisseria sicca. Numbers flanked by dotted arrows specify distances in base pairs between adjacent start- and stop codons. Triangles illustrate various DNA uptake signal sequences: $\mathbf{~ : ~ G C C G T C T G A A ; ~}$

GTCGTCTGAA; : GCCGTTTGAA; : GCCGTCCGAA; : GCCGTATGAA; : ACCGTCTGAA; : ATCGTCTGAA.

Triangles pointing towards each other illustrate inverted repeats. For the complete nucleotide sequences, see Additional file. downstream of folP. The direction of tyrB and the following genes in relation to folP was also the opposite compared to the case in N. subflava/N. sicca/N. mucosa. This indicates that the difference in gene organization was due to an inversion of a genomic segment consisting of the folP gene and the region between folP and tyrB. Another interesting observation was that the distance between folP and the upstream gene in N. lactamica was longer than in other species, due to the insertion of a Correia element. This Correia element was identical to some of the elements found in pathogenic Neisseriae. It had the typical features for these repeats: it was flanked by TA repeats, had a putative integration host factor binding site and its length and inverted terminal repeats indicated that it belonged to the $\alpha$ family of Correia elements [13].

\section{Presence of the aroX gene}

Two of the meningococcal strains (MC58 and 8013) and $N$. gonorrhoeae FA1090 had a putative chorismate mutaserelated gene (aroX) immediately upstream of folP followed by a putative asmA gene (see Figure 1 ). The third meningococcal strain (Z2491), N lactamica and N. cinerea lacked aroX in this position and instead had asmA next to folP. PCR analysis revealed that $\operatorname{aro} X$ was present upstream of folP in six out of eight clinical strains examined (see Figure 2). Interestingly, the two clinical strains lacking aroX both had folP genes identical to Z2491. This folP allele is associated with sulfonamide resistance [5] and displays a very high degree of sequence divergence surrounding the start codon of the gene, compared to other meningococci: 26 altered positions in a 61 base pairs sequence. In fact, this divergent part was almost identical to corresponding sequences in $N$. cinerea and $N$. lactamica, suggesting that horizontal transfer from one of these commensal species removed the aroX gene and simultaneously altered the "wild type" meningococcal sequence immediately upstream of, and the first part of, folP.

\section{Difference in DNA uptake signal sequences}

The complete $6.8 \mathrm{~kb}$ sequence obtained from N. subflava and the intergenic regions amplified by PCR from N. sicca, $N$. lactamica and $N$. cinerea were examined for presence of the neisserial DNA uptake signal sequence (DUS) 5'GCCGTCTGAA-3'. The meningococcal and gonococcal genomes contain almost 2000 copies of this sequence, which makes an average of one copy every 1,100 base pairs. The intergenic sequences from $N$. lactamica and $N$. cinerea were highly similar to the corresponding regions from the pathogenic species, including the numbers and positions of DUS (see Figure 3). In contrast, only one copy of the neisserial DUS was found in the $N$. subflava sequence and none was found among the N. sicca intergenic sequences. However, an altered variant where the second base is a thymine ( 5 -GTCGTCTGAA-3') was more prevalent in the latter species: $N$. subflava displayed as 
Table I: Oligonucleotides used as PCR primers.

\begin{tabular}{cc}
\hline name & sequence (reference) \\
\hline cytup & 5'-TAACGATACCGCTCACAAGGG-3' \\
dedAup & 5'-GTCAAATCTTCGGGAATCGG-3' \\
NMI0 & [42] \\
NMII & CCGCCGCCACGCTGCCGTGT \\
NM7 & TTGGCAGGCAGGACGGTTTG \\
NmAsmup & 5'-CATATTTCAGACGGTATTTGTGG-3' \\
NmdusCrev & CCTTTTCAGACGGCATGAAGTATGTGAACC \\
Nmdusfwd & GTTTTTTATTTGGGAGGAGTTC \\
NmdusTrev & CCTTTTCAGACGACATGAAGTATGTGAACC \\
NmdusXrev & CCTTTTGTGAGTGCATGAAGTATGTGAACC \\
Nsfcytokroml & 5'-TATCGCGCAAGGCTTCGATAC-3' \\
Nsfcytokrom2 & 5'-TAACGCCATGCCTGCAAAAG-3' \\
Nsfcytokrom3 & 5'-AGAAACCCTGCACAAACACG-3 \\
Nsfcytokrom5 & 5'-AACGCCATGCCTGCAAAAG-3' \\
Nsfdownsense3 & 5'-CAGGTTTCCCGCTGTTGATCG-3' \\
Nsfmutasdown2 & 5'-TGCGCATCCAAAAAGGTCAG-3' \\
Nsfmutasdown3 & 5'-AAAGACGTGTTGGCGGAAGTG-3' \\
Nsfmutasdown4 & 5'-GGGAACGGTGGTACAGTGGAT-3' \\
Nsfmutasdown5 & 5'-CCATGCCGGTTTAAGGTTAAT-3' \\
Nsfmutasfwd6 & TATTCCGACAACGGCATCAAATTC \\
Nsfmutasfwd7 & 5'-GTGAAGCTGAGCGATGAAATCGAG-3' \\
Nsfmutasrev5 & 5'-GTCGATTTTGGCTTCGATTTCC-3' \\
NsftyrBdownI & 5'-GATTGAGCGTGGAACAAGTCCG-3' \\
NsftyrBdown2 & 5'-ATTCCGGCAGGATGTGCGTC-3' \\
NsftyrBfwdI & 5'-ACCGGCGTGGATATGTCGG-3' \\
NsftyrBup & 5'-GGTCGTTTTTGAAGGTTTCGAC-3' \\
Nsfupanti & 5'-GTTTGGGCGTTTTGCGAATA-3' \\
\hline
\end{tabular}

many as 10 copies of this altered DUS (see Figure 3; three of the altered DUS are located outside of the displayed sequences) and 6 copies was found in N. sicca. The occurrence of the neisserial and the altered DUS in the folP region of various Neisseria species is listed in the left part of Table 2.

To extend the analysis beyond the folp region, all sequences from human Neisseria species that were larger than 400 base pairs and deposited in the GenBank as of October 2005, were screened for both types of DUS described above. As a comparison, we also searched for another variant of DUS, where the third nucleotide was a thymine (5'-GCTGTCTGAA-3'). The results are summarized in the right part of Table 2. The altered DUS 5'GTCGTCTGAA-3' was detected in the pathogenic Neisseria genomes and in sequences from $\mathrm{N}$. cinerea, N. subflava, N. mucosa and N. elongata, but not as frequent as found around folP in N. subflava and N. sicca. Furthermore, all species also had several copies of the neisserial DUS, present at a much higher density than the altered variant. This indicates that the neisserial DUS is the prevalent one in all Neisseria species, and contradicts our finding from the folP region in N. subflava and N. sicca. When looking at this region in other species, several different variants of DUS can be identified (see Figure 3). For exam- ple, the region upstream of folP displays four variants of DUS: the neisserial DUS, the altered DUS and two other variants. The last column in Table 2 lists the prevalence of a DUS with an altered third base: this variant was also found in most Neisseria species. Obviously, the genomes of Neisseria species contain multiple variants of DUS, which seem to be scattered in variable densities throughout the genomes.

\section{Transformation with DNA containing altered DUS}

The transformation efficiency for DNA containing the neisserial DUS (5'-GCCGTCTGAA-3') and the altered DUS (5'-GTCGTCTGAA-3') was determined for N. meningitidis strain 952. Transformation frequencies were highest for DNA containing the neisserial DUS and around 50\% lower for DNA with the altered DUS. However, the absolute transformation frequencies varied between experiments, so there was no statistically significant difference between the two DUS variants (see Table 3). DNA with a distorted DUS variant, where four bases had been replaced, scored significantly lower values, indicating that the DNA uptake was indeed sequence dependent, as expected in $N$. meningitidis. The conclusion from these experiments was therefore that a one-base-substitution in the DUS did not produce a significant reduction in transformation frequency in this laboratory setting.

\section{Discussion}

The Neisseria species are believed to be non-clonal bacteria with a high degree of genetic transfer within and between different species [2,3,14-18]. Previous reports of transformation in N. meningitidis have suggested that different regions of the genome may have different recombination rates $[19,20]$. This work identified the region upstream of folP as particularly active in recombination events. The most obvious example is the insertion of a complete Correia element, upstream of folP in N. lactamica. Correia elements are small putative transposable elements, around 152 base pairs long with inverted repeats at the ends [12]. Hundreds of Correia copies are scattered around the genomes of pathogenic Neisseriae $[13,21,22]$ and they have also been reported in N. lactamica [23]. We detected another copy of a Correia repeat in the N. subflava sequence, suggesting that these elements are ubiquitous in the Neisseria genus and possibly was introduced before the divergence into different species.

Another example of recombination events is the apparent inversion of a genomic segment in N. subflava, N. sicca and N. mucosa, with one breakpoint upstream of folP. A third recombination event in the same location is the deletion of aroX from some strains. This gene is obviously not essential since it is absent from the genome of N. meningitidis Z2491, but was nevertheless present in the majority of strains examined in this work. The sequences between 
folP and aroX from all these latter strains are highly similar and include two DUS downstream of aroX, arranged as an inverted pair followed by a stretch of thymidines. This arrangement is characteristic of transcription terminators and is a general configuration for DUS in meningococcal and gonococcal genomes $[8,24]$. The strains lacking aro $X$ had retained this putative termination signal, although located between two divergently operating start codons and hence without function. Furthermore, all commensal strains examined in this work also had inverted repeated DUS between the start codons of folP and the upstream gene (tyrB or asmA). These observations support the proposed genetic rearrangements in these species: a deletion of aroX in N. lactamica, N. cinerea and some meningococcal strains, and an inversion of a genomic segment in $N$. subflava, N. mucosa and N. sicca.

The sequence differences and similarities detected in this work could divide the examined species into two groups, where the pathogenic species, $N$. lactamica and $N$. cinerea fall in one group and N. subflava, N. sicca and N. mucosa in a second group. This is in agreement with the classic taxonomy of Neisseria species based on ribosomal RNA hybridization [25,26] and phenotypic tests [27]. The inversion of the folP-tyrB genomic fragment and the accumulation of the altered DUS likely occurred in a common ancestor to N. subflava,N. sicca and N. mucosa. Similarly, the deletion of aroX probably occurred in a common ancestor to N. lactamica and N. cinerea, but after the separation of commensal species from pathogenic species. The removal of aroX created a novel intergenic sequence that was later transferred to a meningococcus, removing $\operatorname{aro} X$ also in this strain. The fact that all meningococcal strains we found lacking aroX were sulfonamide-resistant and had identical folP genes can be explained in three ways: either, the recipient was already sulfonamide-resistant at the time of transfer; the recipient acquired resistance after the transfer; or the donor was a sulfonamide-resistant commensal strain that transferred the resistant folP allele together with the upstream region to the meningococcus.

The DNA uptake signal sequence (DUS) is crucial for efficient transformation in pathogenic Neisseriae $[7,8]$. The tendency to preferentially take up DNA from closely related species was noted in early experiments with gonococci [28-31]. Further experiments established that this was due to the presence of an uptake signal sequence in the donor DNA, and this sequence was subsequently determined to be 5'GCCGTCTGAA-3' [7,8,32]. The meningococcal and gonococcal genomes contain close to 2,000 copies of this neisserial DUS, but they also contain several variants of this sequence with one or a few base substitutions. The altered variants of DUS are frequently located in pairs as perfect inverted repeats after open reading frames, just as the neisserial DUS. This could indicate that this arrangement is important for its function and therefore support the hypothesis of DUS as being transcription terminators [24]. The DUS variant with a thymine in second position was highly prevalent in the folP region of N. subflava and N. sicca, where it seemingly had replaced the neisserial DUS, and was also fairly abundant in pathogenic strains: 165 and 118 copies in N. meningitidis MC58 and N. gonorrhoeae FA1090, respectively. The results from our transformation experiments, albeit per-

Table 2: Presence of DNA uptake signal sequences in human Neisseria species.

\begin{tabular}{|c|c|c|c|c|c|c|}
\hline \multirow[b]{3}{*}{ Species } & \multicolumn{6}{|c|}{ Prevalence (density') of DNA uptake signal sequences } \\
\hline & \multicolumn{2}{|c|}{$\begin{array}{l}\text { in intergenic parts of the folP } \\
\text { region (Fig. 3) }\end{array}$} & \multicolumn{4}{|c|}{ in database sequences } \\
\hline & GCCGTCTGAA & GICGTCTGAA & $\begin{array}{l}\text { Sequence } \\
\text { length }\end{array}$ & GCCGTCTGAA & GICGTCTGAA & GCIGTCTGAA \\
\hline N. meningitidis ${ }^{2}$ & 6 & 0 & $2,272,300$ & $1935(1,174)$ & $165(13,772)$ & $47(48,347)$ \\
\hline N. gonorrhoeae & 7 & 0 & $2,153,894$ & $1965(1,096)$ & $118(18,253)$ & $31(69,480)$ \\
\hline N. lactamica & 7 & 0 & 51,533 & $40(1,288)$ & 0 & 0 \\
\hline N. cinerea & 8 & 0 & 12,158 & $15(811)$ & $3(4,053)$ & $4(3,040)$ \\
\hline N. subflava & 1 & 7 & 13,523 & $16(845)$ & I $(13,523)$ & 0 \\
\hline N. sicca & 0 & 6 & 3,114 & 3 & 0 & 1 \\
\hline N. mucosa & n.a & n.a & 4,492 & 3 & I & I \\
\hline N. polysaccharea & n.a & n.a. & 22,903 & $25(9 \mid 6)$ & 0 & $2(11,452)$ \\
\hline N. flavescens & n.a & n.a & 4,844 & 8 & 0 & 0 \\
\hline N. perflava & n.a & n.a & 1,392 & 2 & 0 & 0 \\
\hline N. elongata & n.a & n.a & 7,064 & 8 & I & 0 \\
\hline
\end{tabular}

I Density as the average distance between two DUS. Density was only calculated when the (accumulated) sequences included more than I0,000 base pairs.

2 Strain MC58 
Table 3: Transformation frequencies

\begin{tabular}{cc}
\hline Type of DUS & Average transformation frequency per 10,000 cells (mean \pm SD) \\
\hline neisserial DUS (GCCGTCTGAA) & $56 \pm 21$ \\
altered DUS (GTCGTCTAA) & $27 \pm 15$ \\
distorted DUS (CGACTCACAA) & $4 \pm 2$ \\
\hline
\end{tabular}

formed with synthetic PCR-products under conditions different from the natural habitat of these bacteria, indicated that this one-base difference in DUS only marginally reduced the transformation frequency. Perhaps this can explain why this particular variant of DUS seems so prevalent in neisserial genomes: this alteration may be well tolerated by the DNA uptake mechanism.

It is not clear why some naturally competent species have a sequence-specific DNA uptake mechanism. One explanation describes their presence as a mere consequence of a preferential uptake of specific sequences during natural transformation [33]: DNA uptake processes that favor a specific sequence automatically lead to an accumulation of this preferred sequence in the genome, because DNA containing this sequence is more likely to be integrated than other DNA. Another theory is that DUS may be beneficial for the bacterial population since it directs the DNA uptake to sequences from closely related bacteria that can be used for creation of genetic variability or for DNA repair. A recent study report a higher frequency of DUS in genome maintenance genes compared to genes of other function, thus supporting the DNA repair explanation [34]. If DUS evolved as a mechanism to obtain homologous DNA for repair purposes it would make sense that only closely related species shared the same DUS. This hypothesis could therefore justify why the neisserial DUS was found in $N$. lactamica and $N$. cinerea, whereas an altered version of DUS was detected in the more distantly related N. subflava and N. sicca. On the other hand, this distinction was only true for the folP region: when examining sequences from other regions the neisserial DUS dominated in all species. However, the sequences available for analysis from several of the commensal species, including N. subflava and N. sicca, are in short supply and not representative for the whole genomes. Obviously, analysis of more sequences from these commensals is required to address the distribution of various DUS within the genomes of commensal Neisseria species.

\section{Conclusion}

This work compared the sequence surrounding the folP gene in various Neisseria species. The results lead to a general differentiation of the examined species into two groups, where $N$. subflava, $N$. mucosa and $N$. sicca belonged to one group and $N$. cinerea, $N$. lactamica, $N$. meningitidis and $N$. gonorrhoeae to another group. The major differences between these two groups were an inversion of DNA with one breakpoint in the upstream region of folP, and a one base pair difference in the DNA uptake signal sequences present in this genomic region. The variability within the folP region may reflect the ongoing selection of different folP alleles by the selective pressure of sulfonamide drug use.

\section{Methods}

\section{Neisseria strains}

The Neisseria meningitidis clinical isolates used in this work were 418, 1014 [35], MO035 [36], 952, BT054, BT227, MO124 [37] and 3976 [38]. The commensal strains were Neisseria lactamica ATCC23970, Neisseria mucosa ATCC19696, Neisseria sicca ATCC9913, Neisseria subflava ATCC19243 and Neisseria cinerea ATCC14685. Bacteria were cultivated on Brain Heart Infusion agar plates (Difco Laboratories, USA) in $10 \% \mathrm{CO}_{2}$.

\section{Reagents}

Oligonucleotides (listed in Table 1) were purchased from Thermo Hybaid, Germany. Restriction enzymes and other molecular biology reagents were purchased from Roche Diagnostics, Germany, if not otherwise stated. Ligation mixtures were transformed into One Shot ${ }^{\circledast}$ TOP10 Chemically Competent E. coli (Invitrogen ${ }^{\mathrm{TM}}$, The Netherlands). PCR products were purified from agarose gels using MinElute Gel Extraction Kit (QIAGEN, Germany) and cloned into $\mathrm{pCR}^{\circledR} 2.1-\mathrm{TOPO}^{\circledast}$ vector (Invitrogen ${ }^{\mathrm{Tm}}$, The Netherlands) according to the manufacturer's instructions. Plasmids were purified using QIAprep Spin Miniprep (QIAGEN, Germany). DNA was sequenced on ABI PRISM 310 Genetic Analyzer (Applied Biosystems, USA) using DYEnamic ET Terminator Cycle Sequencing Kit (Amersham Biosciences, Sweden).

\section{Determination of Neisseria subflava sequence}

PCR primers NM7 and NM11 were used to amplify 734 base pairs of folP from N. subflava ATCC19243. Flanking sequences were determined using a chromosome walking method [39]; Restriction enzyme digested chromosomal DNA (approximately $2 \mu \mathrm{g}$ ) was inserted into vector pUC19 with T4 DNA Ligase (New England Biolabs, Beverly, MA) at $16^{\circ} \mathrm{C}$. The unknown sequence was then amplified with the ligation mixture as template and one vector-specific primer, directed towards the insert, and a sequence-specific primer, directed towards the unknown 
sequence. The polymerase chain reactions contained 0.2 units Taq Polymerase (Fermentas, Lithuania), $0.5 \mu \mathrm{M}$ of each primer, $0.2 \mathrm{mM}$ of each deoxynucleotide and $100 \mathrm{ng}$ of DNA in a 20- $\mu$ l reaction. PCR products were cloned and sequenced as described above. The chromosome walking was repeated stepwise in both directions until a 6808 base pair region of the chromosome had been sequenced. Nested PCR was performed in some of the steps to achieve specific products.

\section{Determination of gene order}

Primers binding within genes but directed towards noncoding regions were utilized to amplify intergenic sequences from chromosomal DNA from all Neisseria strains listed above using the Expand ${ }^{\mathrm{TM}}$ High Fidelity PCR System (Roche, Germany). Primers dedAup and Nsfmutasdown 3 were used to amplify the region between $\operatorname{ded} A$ and manB; Nsfmutasrev5 and NM10 to amplify the region between manB and folP; Nsfupanti and NmAsmAup between folP and asmA; Nsfupanti and NsftyrBup between folP and tyrB; and NsftyrBdown2 and cytup between tyrB and $c y t 5$. PCR products from $N$. lactamica, $N$. cinerea and $N$. sicca were cloned and sequenced as described above.

\section{Transformation frequencies}

The complete folP gene from the sulfonamide-resistant $N$. meningitidis strain MO035 was amplified from chromosomal DNA using the forward primer Nmdusfwd and one of three reverse primers. NmdusCrev was used to incorporate the meningococcal DUS in the PCR-product, NmdusTrev to incorporate the subflava variant of DUS and NmdusXrev to make a control DNA with equal length but with a disrupted DUS. PCR was performed with the Expand $^{\mathrm{TM}}$ High Fidelity PCR System (Roche, Germany) according to the manufacturer's instructions and the products were purified with the MinElute PCR Purification kit (QIAGEN, Germany). The sulfonamide-susceptible N. meningitidis strain 952 was suspended to $\mathrm{OD}_{600}=$ 0.1 in a rich broth containing Brain-Heart-Infusion Blood-Agar Base (Difco Laboratories, USA), $10 \mathrm{mM}$ $\mathrm{MgCl}_{2}, 2 \times$ Kellogg's supplement and $0.042 \% \mathrm{NaHCO}_{3}$ [40]. Exactly $1 \mu \mathrm{g}$ of purified PCR-products was added to $200 \mu \mathrm{l}$ bacterial suspension and the mixture was incubated at $37^{\circ} \mathrm{C}$ in $5 \% \mathrm{CO}_{2}$ until $\mathrm{OD}_{600}=0.3$. The diluted transformation mixtures were incubated on ISA plates (Oxoid, England) with or without $0.25 \mathrm{mM}$ sulfathiazole (Sigma-Aldrich, Sweden).

\section{Sequence data analysis}

The complete genome sequences from pathogenic Neisseria species were extracted from GenBank: AL157959 (strain Z2491), $\underline{\mathrm{NC003112}}$ (MC58) and $\underline{\mathrm{AF} 00969}$ (FA1090). The $5 \mathrm{~kb}$ sequence from $N$. meningitidis strain 8013 was provided by Christophe Rusniok and Philippe
Glaser at the Pasteur Institute, France. The following entries from commensal Neisseria species were extracted from GenBank: N. cinerea: AF158604, Z17308-Z17310, X64869， AJ223935， AJ223913-AJ223915， AJ223890AJ223892, AY831725, AJ704731, AY360352, AF470674, $\underline{\mathrm{AF} 319536}, \underline{\mathrm{AF} 306836}, \underline{\mathrm{AF} 139614}, \underline{\mathrm{AF} 216744}, \underline{\mathrm{AI} 247236}$, AJ239300, AJ239299, AJ239287, AF121876, AF029360,

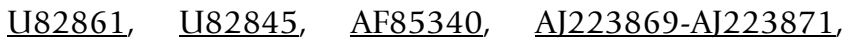
U57906, U57710， X59540; N. elongata: AF121870, DQ007933， AJ223877-AJ223882， AJ223921-AJ223926, AJ223898-AJ223903， AY821559， AY167422， AF542173， AJ247252-AJ247254， AJ239302， AJ239303， AJ239297， AJ239278, AF121870, L06171; N. flavescens: M26645, $\underline{\text { AY174058 }}$, Z22955， X64872， AJ223938， AJ704736,

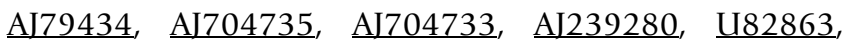
$\underline{\mathrm{U} 82847}, \underline{\mathrm{AF} 987677}, \underline{\mathrm{Y} 09310}, \underline{\mathrm{Y} 09311}, \underline{\mathrm{U}} 57907, \underline{\mathrm{U} 57711}$, L06168; N. lactamica: DQ015867, Y11818, Y11819, $\underline{\mathrm{Y} 10876}, \underline{\mathrm{Y} 10877}, \underline{\mathrm{X} 54485}, \underline{\mathrm{X} 64871}, \underline{\mathrm{AJ} 288888-\mathrm{AJ} 288893}$, AJ223909， AJ223945-AJ223947， AJ223910， AJ223907， AJ223908， AJ223884-AJ223887， AJ223863-AJ223866, NC006968, AY857302-AY857306, AY532623$\underline{\text { AY532628 }}, \underline{\text { AY532630 }}, \underline{\text { AY54849 }}, \underline{\text { AY654848 }}, \underline{\text { AJ704746- }}$ $\underline{\text { AJ704748 }}, \underline{\text { AJ704737, }}$ AY438701, Y134876, AF542177, AJ270921-AJ270932， AJ270918， AJ270906-AJ270908， AJ270902， AJ270900-AJ270904， AF470682， AF470683， $\underline{\mathrm{AF} 470673}, \underline{\mathrm{AY} 038932}, \underline{\mathrm{AF} 319537}, \underline{\mathrm{AJ} 270919}, \underline{\mathrm{AJ} 270920}$, AF312972, $\underline{\text { AF216855 }}, \underline{\mathrm{AF} 158603}, \underline{\mathrm{AJ} 247241}, \underline{\mathrm{AJ} 247242}$,

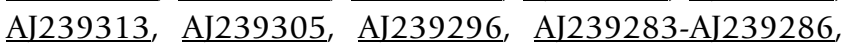
U82843， U82858， AF085689， AJ001737-AJ001740, Y09308， U57709，Y57905， U59398， X74901， X65533， U06074; N. mucosa: AJ223875， X59635， X64873， AJ223937, $\underline{\text { AJ223919 }}$ AJ223896,$\underline{\text { AJ223875 }}$ AJ704738, AY462277， AJ247255-AJ247260， AJ239279， AJ239282, AF121872, U82860, U82848, L47156, U57908, U57901; N. perflava: AJ223920, AJ223906, AJ223897, AJ223883, AJ223876, AI223862, AY837569, AF312973, AJ247246, AJ247247, AJ239295; N. polysaccharea: DQ007935,

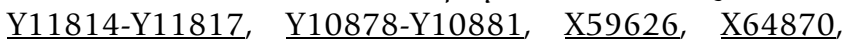
$\underline{\mathrm{AJ} 223944}, \underline{\mathrm{AJ} 223940-\mathrm{AJ} 223943} ， \underline{\text { AJ704761 }}, \underline{\text { AJ704762 }}$ AJ704743, AJ704739-AJ704744, AY134878, AY072807AY072809, AY099335, AF542178, AF216858, AJ239314, $\underline{\mathrm{AJ} 239315}, \underline{\mathrm{AJ} 239298}, \underline{\mathrm{AJ} 239289}, \underline{\mathrm{AJ} 011781}, \underline{\mathrm{U} 82844}$, U82859, Y09309, U57708, U57904, L06167; N. sicca: DQ007936， X76285， AJ223916， AJ223872， AJ223893， AY857301， AJ704730, AF312974， AJ247248， AJ239292AJ239294，Y09307; N. subflava: DQ007937， AJ288894, AJ223918, $\underline{\text { AJ223895 }}, \underline{\mathrm{AJ} 223874}, \underline{\mathrm{AY} 522860}, \underline{\mathrm{AJ} 704745}$, $\underline{\mathrm{AY} 134877}, \underline{\mathrm{AF} 216745}, \underline{\mathrm{AF} 240672}, \underline{\mathrm{AF} 241526}, \underline{\mathrm{AJ} 247249}$, AF470684, AF479577, AF479578, AJ239291. The search for DUS and Correia elements was performed using the DNA Pattern Find algorithm in the Sequence Manipulation Suite [41]. 


\section{Authors' contributions}

YQ participated in the planning of this study, performed all experimental work and drafted the manuscript. GS participated in the planning, coordinated the study, and assisted in writing the manuscript. Both authors have approved the final manuscript.

\section{Additional material}

\section{Additional File 1}

Intergenic sequences from commensal Neisseriae. This document lists the nucleotide sequences from the commensal species that are schematically illustrated in Figure 3.

Click here for file

[http://www.biomedcentral.com/content/supplementary/14712180-6-11-S1.htm]

\section{Acknowledgements}

We are grateful to Christophe Rusniok and Philippe Glaser at the Pasteur Institute for providing the DNA sequence from N. meningitidis strain 8013 . This work was supported by a grant from the AFA Health Foundation in Sweden.

\section{References}

I. Holmes EC, Urwin R, Maiden MC: The influence of recombination on the population structure and evolution of the human pathogen Neisseria meningitidis. Mol Biol Evol 1999, 16(6):741-749.

2. Feil EJ, Maiden MC, Achtman M, Spratt BG: The relative contributions of recombination and mutation to the divergence of clones of Neisseria meningitidis. Mol Biol Evol 1999, I6(II): | 496-1502.

3. Linz B, Schenker M, Zhu P, Achtman M: Frequent interspecific genetic exchange between commensal Neisseriae and Neisseria meningitidis. Mol Microbiol 2000, 36(5): 1049-1058.

4. Bowler LD, Zhang QY, Riou JY, Spratt BG: Interspecies recombination between the penA genes of Neisseria meningitidis and commensal Neisseria species during the emergence of penicillin resistance in $\mathbf{N}$. meningitidis: natural events and laboratory simulation. J Bacteriol I994, I 76(2):333-337.

5. Fermer C, Kristiansen BE, Skold O, Swedberg G: Sulfonamide resistance in Neisseria meningitidis as defined by sitedirected mutagenesis could have its origin in other species. J Bacteriol 1995, 177(16):4669-4675.

6. Qvarnstrom Y, Swedberg G: Sulphonamide resistant commensal Neisseria with alterations in the dihydropteroate synthase can be isolated from carriers not exposed to sulphonamides. BMC Microbiol 2002, 2(I):34.

7. Elkins C, Thomas CE, Seifert HS, Sparling PF: Species-specific uptake of DNA by gonococci is mediated by a 10-base-pair sequence. J Bacteriol | 991, I73(1 2):39|1-39/3.

8. Goodman SD, Scocca JJ: Identification and arrangement of the DNA sequence recognized in specific transformation of Neisseria gonorrhoeae. Proc Natl Acad Sci U S A 1988, 85(18):6982-6986.

9. Tettelin H, Saunders NJ, Heidelberg J, Jeffries AC, Nelson KE, Eisen JA, Ketchum KA, Hood DW, Peden JF, Dodson RJ, Nelson WC, Gwinn ML, DeBoy R, Peterson JD, Hickey EK, Haft DH, Salzberg SL, White O, Fleischmann RD, Dougherty BA, Mason T, Ciecko A, Parksey DS, Blair E, Cittone H, Clark EB, Cotton MD, Utterback TR, Khouri H, Qin H, Vamathevan J, Gill J, Scarlato V, Masignani V, Pizza M, Grandi G, Sun L, Smith HO, Fraser CM, Moxon ER, Rappuoli R, Venter JC: Complete genome sequence of Neisseria meningitidis serogroup B strain MC58. Science 2000, 287(5459): $1809-1815$.
10. Parkhill J, Achtman M, James KD, Bentley SD, Churcher C, Klee SR, Morelli G, Basham D, Brown D, Chillingworth T, Davies RM, Davis P, Devlin K, Feltwell T, Hamlin N, Holroyd S, Jagels K, Leather S, Moule S, Mungall K, Quail MA, Rajandream MA, Rutherford KM, Simmonds M, Skelton J, Whitehead S, Spratt BG, Barrell BG: Complete DNA sequence of a serogroup $A$ strain of Neisseria meningitidis Z249 I. Nature 2000, 404(6777):502-506.

II. Neisseria gonorrhoeae Genome Sequencing Strain FA 1090 [http://www.genome.ou.edu/gono.html]

12. Correia FF, Inouye S, Inouye M: A family of small repeated elements with some transposon-like properties in the genome of Neisseria gonorrhoeae. I Biol Chem 1988, 263(25): $12194-12198$.

13. Buisine N, Tang CM, Chalmers R: Transposon-like Correia elements: structure, distribution and genetic exchange between pathogenic Neisseria sp. FEBS Lett 2002, 522(13):52-58.

14. Feil EJ, Holmes EC, Bessen DE, Chan MS, Day NP, Enright MC, Goldstein R, Hood DW, Kalia A, Moore CE, Zhou J, Spratt BG: Recombination within natural populations of pathogenic bacteria: short-term empirical estimates and long-term phylogenetic consequences. Proc Natl Acad Sci U S A 200 I, 98(I): 182-187.

15. Smith JM, Smith NH, O'Rourke M, Spratt BG: How clonal are bacteria? Proc Natl Acad Sci U S A 1993, 90( I 0):4384-4388.

16. Zhu P, Klutch MJ, Bash MC, Tsang RS, Ng LK, Tsai CM: Genetic diversity of three Igt loci for biosynthesis of lipooligosaccharide (LOS) in Neisseria species. Microbiology 2002, I48(Pt 6): $1833-1844$.

17. Maiden MC, Malorny B, Achtman M: A global gene pool in the neisseriae. Mol Microbiol 1996, 2 1(6): I297-I298.

18. Morelli G, Malorny B, Muller K, Seiler A, Wang JF, del Valle J, Achtman $M$ : Clonal descent and microevolution of Neisseria meningitidis during 30 years of epidemic spread. Mol Microbiol 1997, 25(6): 1047-1064.

19. Feil E, Zhou J, Maynard Smith J, Spratt BG: A comparison of the nucleotide sequences of the adk and recA genes of pathogenic and commensal Neisseria species: evidence for extensive interspecies recombination within adk. J Mol Evol 1996, 43(6):63I-640.

20. Claus H, Frosch M, Vogel U: Identification of a hotspot for transformation of Neisseria meningitidis by shuttle mutagenesis using signature-tagged transposons. Mol Gen Genet 1998, 259(4):363-37I.

21. Liu SV, Saunders NJ, Jeffries A, Rest RF: Genome analysis and strain comparison of correia repeats and correia repeatenclosed elements in pathogenic Neisseria. J Bacteriol 2002, 184(22):6163-6173.

22. Mazzone M, De Gregorio E, Lavitola A, Pagliarulo C, Alifano P, Di Nocera PP: Whole-genome organization and functional properties of miniature DNA insertion sequences conserved in pathogenic Neisseriae. Gene 200I, 278(I-2):2 I I-222.

23. De Gregorio E, Abrescia C, Carlomagno MS, Di Nocera PP: Asymmetrical distribution of Neisseria miniature insertion sequence DNA repeats among pathogenic and nonpathogenic Neisseria strains. Infect Immun 2003, 7 I (7):42 17-422I.

24. Smith HO, Gwinn ML, Salzberg SL: DNA uptake signal sequences in naturally transformable bacteria. Res Microbiol 1999, I50(910):603-616.

25. Guibourdenche M, Popoff MY, Riou JY: Deoxyribonucleic acid relatedness among Neisseria gonorrhoeae, $N$. meningitidis, N. lactamica, N. cinerea and "Neisseria polysaccharea". Ann Inst Pasteur Microbiol 1986, I37B(2): I77-I85.

26. Rossau R, van den Bussche G, Segers P, Grosch H, Göthe E, Mannheim W, de Ley J: Ribosomal ribonucleic acid cistron similarities and deoxyribonucleic acid homologies of Neisseria, Kingella, Eikenella, Simonsiella, Alysiella, and Centers for Disease Control groups EF-4 and M-5 in the emended family Neisseriaceae. Int J Syst Bacteriol 1989, 39:185-198.

27. Barrett SJ, Sneath PH: A numerical phenotypic taxonomic study of the genus Neisseria. Microbiology 1994, I40 ( Pt (0):2867-289|.

28. Dougherty TJ, Asmus A, Tomasz A: Specificity of DNA uptake in genetic transformation of gonococci. Biochem Biophys Res Commun 1979, 86(I):97-104.

29. Roberts M, Piot P, Falkow S: The ecology of gonococcal plasmids. J Gen Microbiol 1979, I I4(2):49I-494. 
30. Graves JF, Biswas GD, Sparling PF: Sequence-specific DNA uptake in transformation of Neisseria gonorrhoeae. J Bacteriol 1982, I52(3): 107|-1077.

31. Mathis LS, Scocca Jl: Haemophilus influenzae and Neisseria gonorrhoeae recognize different specificity determinants in the DNA uptake step of genetic transformation. J Gen Microbiol 1982, I 28(5): I |59-I I6I.

32. Burnstein KL, Dyer DW, Sparling PF: Preferential uptake of restriction fragments from a gonococcal cryptic plasmid by competent Neisseria gonorrhoeae. J Gen Microbiol 1988, I 34(3):547-557.

33. Bakkali M, Chen TY, Lee HC, Redfield RJ: Evolutionary stability of DNA uptake signal sequences in the Pasteurellaceae. Proc Natl Acad Sci U S A 2004, I 0 I (13):45 I3-45 I8.

34. Davidsen T, Rodland EA, Lagesen K, Seeberg E, Rognes T, Tonjum T: Biased distribution of DNA uptake sequences towards genome maintenance genes. Nucleic Acids Res 2004, 32(3): $1050-1058$.

35. Salih MA, Danielsson D, Backman A, Caugant DA, Achtman M, Olcen $P$ : Characterization of epidemic and nonepidemic Neisseria meningitidis serogroup A strains from Sudan and Sweden. J Clin Microbiol 1990, 28(8): I7II-I7I9.

36. Kristiansen BE, Radstrom P, Jenkins A, Ask E, Facinelli B, Skold O: Cloning and characterization of a DNA fragment that confers sulfonamide resistance in a serogroup $B$, serotype 15 strain of Neisseria meningitidis. Antimicrob Agents Chemother I990, 34(I I):2277-2279.

37. Radstrom P, Fermer C, Kristiansen BE, Jenkins A, Skold O, Swedberg G: Transformational exchanges in the dihydropteroate synthase gene of Neisseria meningitidis: a novel mechanism for acquisition of sulfonamide resistance. J Bacteriol 1992, I 74(20):6386-6393.

38. Kristiansen BE, Fermer C, Jenkins A, Ask E, Swedberg G, Skold O: PCR amplicon restriction endonuclease analysis of the chromosomal dhps gene of Neisseria meningitidis: a method for studying spread of the disease-causing strain in contacts of patients with meningococcal disease. I Clin Microbiol 1995, 33(5): II74- II79.

39. Kneidinger B, Graninger M, Messner P: Chromosome walking by cloning of distinct PCR fragments. Biotechniques 2001, 30(2):248-249.

40. Gunn JS, Stein DC: Use of a non-selective transformation technique to construct a multiply restriction/modification-deficient mutant of Neisseria gonorrhoeae. Mol Gen Genet 1996 , 25 I (5):509-5I 7.

41. Stothard P: The sequence manipulation suite: JavaScript programs for analyzing and formatting protein and DNA sequences. Biotechniques 2000, 28(6): I I 02, I I 04.

42. Qvarnstrom Y, Swedberg G: Additive effects of a two-aminoacid insertion and a single-amino-acid substitution in dihydropteroate synthase for the development of sulphonamideresistant Neisseria meningitidis. Microbiology 2000, I46 ( Pt 5): || $5|-| \mid 56$
Publish with BioMed Central and every scientist can read your work free of charge

"BioMed Central will be the most significant development for disseminating the results of biomedical research in our lifetime. "

Sir Paul Nurse, Cancer Research UK

Your research papers will be:

- available free of charge to the entire biomedical community

- peer reviewed and published immediately upon acceptance

- cited in PubMed and archived on PubMed Central

- yours - you keep the copyright

Submit your manuscript here:

http://www.biomedcentral.com/info/publishing_adv.asp
BioMedcentral 